\title{
COMPARISON OF THE EFFICACY OF ANTIBIOTIC-STEROID AND ICHTHAMMOL GLYCERINE WICK IN TREATMENT OF ACUTE OTITIS EXTERNA
}

\author{
Maryam Khan, Kamran Ashfaq Ahmed Butt*, Naeem Riaz**, Zaheer Ul Hassan*, Attique Ahmed***, Muhammad Wasif**** \\ Hayatabad Medical Complex, Peshawar Pakistan, *Combined Military Hospital Peshawar/National University of Medical Sciences (NUMS) Pakistan, \\ **Pak Naval Ship Shifa Hospital, Karachi Pakistan, ${ }^{* * *}$ Combined Military Hospital Lahore/National University of Medical Sciences (NUMS) Pakistan, \\ ****Combined Military Hospital Chunian/National University of Medical Sciences (NUMS) Pakistan
}

\begin{abstract}
Objective: To compare the efficacy of steroid antibiotic wick with Ichthammol Glycerol wick in the management of Acute Otitis Externa in terms of tenderness and clearance of discharge/debris.

Study Design: Quasi-experimental study.

Place and Duration of Study: ENT Out Patient department of Combined Military Hospital Peshawar and Hayatabad Medical Complex Peshawar, from May to Nov 2018.

Methodology: A total of 250 patients were included and divided into two groups of 125 each. After necessary suction clearance topical Ciprofloxacin/Dexamethasone (Cipotec-D) wick was placed in auditory canal of group A patients and topical Glycerol/Ichthammol wick was placed in group B. Follow up visits were done on 3rd and 7th day of starting the treatment. Results: Group A patients responded better in terms of tenderness (88\%) however both groups had similar response in terms of discharge reduction $(7.2 \%$ vs $6.4 \%)$. In terms of efficacy neither of the treatment proved more efficacious compared to the other ( $p$-value 0.058$)$.

Conclusion: While steroid antibiotic wick is significantly more efficient in terms reducing tenderness, in terms of overall efficacy and discharge reduction Ichthammol/glycerol is equally effective.
\end{abstract}

Keywords: Bacterial otitis externa, Ciprofloxacin/dexamethasone wick, Glycerol/ichthammol wick.

How to Cite This Article: Khan M, Butt KAA, Riaz N, Hassan ZU, Ahmed A, Wasif M. Comparison of the Efficacy of Antibiotic-Steroid and Ichthammol Glycerine Wick in Treatment of Acute Otitis Externa. Pak Armed Forces Med J 2021; 71 (Suppl-3): S612-616.

Doi: https://doi.org/10.51253/pafmj.v1i1.4556

This is an Open Access article distributed under the terms of the Creative Commons Attribution License (https://creativecommons.org/licenses/by-nc/4.0/), which permits unrestricted use, distribution, and reproduction in any medium, provided the original work is properly cited.

\section{INTRODUCTION}

Inflammation of the skin of the external auditory canal is known as otitis externa (OE). While it is usually bacterial in origin, fungal infection can be a cause occasionally. Contact dermatitis, eczema and seborrhea are some examples of a variety of local dermatological or non infective systemic causes associated with otitis externa. ${ }^{1}$

OE has a life time incidence of $10 \%$ in population. $^{2}$ Discomfort; aural fullness and pain restricted to external auditory canal are the most distinctive symptoms while erythema and edema of the external auditory canal in the presence or absence of discharge are the commonest signs. Untreated immunocompromised patients (Diabetics \& AIDS) of otitis externa can end up developing malignant otitis externa which involves the spread of infection beyond the confines of External Auditory Canal (EAC) involving bone and soft tissues. ${ }^{3}$ Other complications that can result from otitis externa include cellulitis, atresia of external auditory canal and perichondritis. Gram positive organisms

Correspondence: Dr, Kamran Ashfaq Ahmed Butt, ENT Department, Combined Military Hospital Peshawar-Pakistan specifically staphylococcus aureus, pseudomonas aeruginosa and proteus as well as gram negative organisms have been cultured in cases of otitis externa. ${ }^{4}$

Methicillin resistant staphylococcus aureus though reported in literature occasionally pose no specific management problem as long as systemic involvement does not occur. ${ }^{5}$ Various authors have noted that pseudomonas aeruginosa strains in cases of aural diseases are different from the strains found elsewhere in the body which may affect the treatment offered. Most complicated cases of otitis externa are due to poor socioeconomic status, lack of education and ignorance about the disease or a combination of the above factors. ${ }^{6}$

Uncomplicated cases of otitis externa do not require any systemic anti biotic therapy. Topical antibiotic/steroid drops or sprays can be used. The role of steroids in such patients is to reduce inflammation and edema of the ear canal which is the main reason for the most disturbing symptoms. In sensitive individuals aural medication can cause stinging or burning and topical sensitivity which leads to decreased compliance. These individuals are more prone to progress to resistant or recurrent cases. 3,7 
Glycerol/Icthammol is a commonly used, easily and cheaply available solution used as an aural wick in cases of bacterial otitis externa. It not only has proven activity against staphylococci and streptococci but is also an effective dehydrating and anti inflammatory solution. Its dehydrating properties reduce canal edema and indirectly reduce pain; however oral analgesics are still necessary in moderate to severe cases. Sensitivity to Ichthammol/glycerol is relatively uncommon thereby making it an effective medication in atopic individuals. ${ }^{3,8}$

Various studies done previously have shown $87 \%$ response to Ichthammol/Glycerol wick while literature shows a $97 \%$ response in cases where Ciprofloxacin/Dexamethasone combination was used for management of acute bacterial otitis externa. ${ }^{9,10}$

Our study involves comparison of Ciprofloxacin/ Dexamethasone wick with topical Glycerol/Ichthammol wick to establish their efficacy in treatment of bacterial otitis externa. This will help us in reducing unnecessary use of medication and make treatment more effective in terms of patient compliance and symptomatic relief.

\section{METHODOLOGY}

This quasi-experimental study was conducted at Combined Military Hospital Peshawer and ENT Unit-A HMC Peshawer simultaneously, from May to Nov 2018. Sample size was calculated by WHO sample size calculator 2.2a which was 250 i.e., 125 patients in each group, keeping P1 97\%, P2 87\%, power 90\% and level of significance $5 \%$. Non probability con-secutive sampling technique was used for sample sel-ection.

Inclusion criteria: All patients of both genders above 12 years of age with diagnosis of acute otitis externa were included in the study.

Exclusion criteria: Patients having prior history of acute/chronic Suppurative otitis media, Malignant otitis externa, bilateral otitis externa, local allergic conditions such as eczema and psoriasis, diabetes mellitus or other immunocompromised states and using hearing aids with bilateral Otitis externa were excluded from the study.

Permission was sought from hospital ethical committee via IERC no. ${ }^{5}$ Three hundred patients were selected after detailed history and physical examination on 1st visit. Informed written consent was taken from all the patients. Hospital registration number, name, gender, age, address and phone number (optional) were noted for future communication. History for pain, discharge, use of hearing aid, diabetes and allergy was taken. Patients were examined for tenderness and presence of discharge/debris. Abnormalities of tympanic membrane were excluded. Selected patients were randomly divided into 2 groups of 125 each using random number table. Group A were treated with Ciprofloxacin-Dexamethasone soaked wick (steroid-antibiotic wick) placement in affected ear with advice to regularly instill drops on wick for next three days. Group B were treated with Icthammol Glycerine wick placement in affected ear with advice to regularly instill Icthammol Glycerine oil on wick for next three days. The patients were called on 3rd day for wick replacement and aural toilet followed by reexamination of the external auditory canal on 7th day was done by the research team. Patients were examined for tenderness and presence of discharge/debris. Abnormalities of tympanic membrane were excluded. On follow up visit (7th day) response to treatment was observed in terms of tenderness (presence/absence) and debris/ discharge (presence/absence). All the variables were noted on a data collection performa.

SPSS-16 was used for data analysis. Quantative data like age were analyzed as mean and standard deviation while the qualitative data like gender, tenderness and discharge/debris were measured as percentage and frequency. The difference of tenderness and presence or absences of discharge/debris between the two study groups were tested. Efficacies of both groups were compared using the chi square test. $p$ value $\leq 0.05$ was considered significant.

\section{RESULTS}

A total of 250 patients were included in the study which was performed. Patients were divided into groups A and B. After necessary suction and clearance $3 \mathrm{~cm}$ long ciprofloxacin/dexamethasone wick was placed in the affected ear of group A patients while $3 \mathrm{~cm}$ long Icthammol/Glycerol wick was placed in the affected ear of the group $B$ patients.

Out of 250 patients 137 (54.8\%) were male while $113(45.2 \%)$ were female. Average age of the patients was 39.85 years and varied from 11-80 years with a standard deviation of 17.2.

Presence or absence of tenderness was noted in both groups at the time of presentation and once again on the 7th day. All the patients had tenderness on the day of presentation. This was improved by $88 \%$ in group A patients where only 15 patients still had tenderness on the 7 th day. In group B $78.4 \%$ of the patients experienced improvement in signs and tender- 
ness was absent on day 7 while 27 patients still had tenderness on day. ${ }^{7}$ This difference was statistically significant as $p$-value was 0.04 . There was no predilection for any gender with regards to tenderness in both groups.

At initial presentation all the patients had discharge/debris occluding the external auditory canal and suction clearance had to be performed. On the 7th day of treatment only 9 patients $(7.2 \%)$ still had discharge and debris in group A while 8 patients $(6.4 \%)$ had persistent discharge in their EAC in Icthammol/ Glycerol group. This difference was statistically not significant as $p$-value was 0.8 . Male or female gender did not affect the presence or absence of discharge in both groups.

With regards to the efficacy a treatment was efficacious if there was an absence of discharge and tenderness at the visit on 7th day. In this context Ciprofloxacin/Dexamethasone combination was effective in $106(84.8 \%)$ patients while Icthammol/Glycerine was effective in $94(75.2 \%)$ patients. However this difference was not significant as $p$-value came out at 0.058 . There was no difference in efficacy between both groups in terms of gender. $p$-value was also insignificant as shown in Table-I.

Table-I: Gender wise distribution of patients in the both groups.

\begin{tabular}{c|l|c|c}
\hline \multirow{2}{*}{ Groups } & & \multicolumn{2}{|c}{ Gender } \\
\cline { 3 - 4 } & & Male & Female \\
\hline \multirow{2}{*}{$\mathrm{A}$} & Patients treated with ciproflo- & 70 & 55 \\
& xacin/dexamethasone wick & $(56 \%)$ & $(44 \%)$ \\
\hline \multirow{2}{*}{$\mathrm{B}$} & Patients treated with & 67 & 58 \\
& Glycerol/Ichthammol wick & $(53.6 \%)$ & $(47.4 \%)$ \\
\hline
\end{tabular}

Table-II: Comparison of tenderness \& debris/discharge in both groups.

\begin{tabular}{|c|c|c|c|c|c|}
\hline & & & $\begin{array}{c}\text { Group A } \\
\text { n ( }(\%)\end{array}$ & $\begin{array}{c}\text { Group B } \\
\text { n ( }(\%)\end{array}$ & $\begin{array}{c}p- \\
\text { value }\end{array}$ \\
\hline \multirow{4}{*}{$\begin{array}{l}\text { Tender- } \\
\text { ness }\end{array}$} & \multirow{2}{*}{$\begin{array}{c}\text { At } \\
\text { Presen- } \\
\text { tation }\end{array}$} & Present & $125(100)$ & $125(100)$ & \multirow[b]{2}{*}{0.5} \\
\hline & & Absent & - & - & \\
\hline & \multirow{2}{*}{ At day 7} & Present & $15(12)$ & $27(21.6)$ & \multirow{2}{*}{0.042} \\
\hline & & Absent & $110(88)$ & $98(78.4)$ & \\
\hline \multirow{4}{*}{$\begin{array}{l}\text { Debris/ } \\
\text { Dis- } \\
\text { charge }\end{array}$} & \multirow{2}{*}{$\begin{array}{c}\text { At } \\
\text { Presen- } \\
\text { tation }\end{array}$} & Present & $125(100)$ & $125(100)$ & \multirow[b]{2}{*}{0.5} \\
\hline & & Absent & - & - & \\
\hline & \multirow{2}{*}{ At day 7} & Present & $9(7.2)$ & $8(6.4)$ & \multirow{2}{*}{0.802} \\
\hline & & Absent & $116(92.8)$ & $117(93.6)$ & \\
\hline
\end{tabular}

Group-A: Patients treated with Ciprofloxacin/Dexamethasone wick, Group-B: Patients treated with Glycerol/Icthammol wick

Table-III: Efficacy of treatment between both groups.

\begin{tabular}{l|c|c|c}
\hline Group & Effective & Not Effective & $p$-value \\
\hline A & $106(84.8 \%)$ & $19(15.2 \%)$ & \multirow{2}{*}{0.058} \\
\hline B & $94(75.2 \%)$ & $31(24.8 \%)$ & \\
\hline
\end{tabular}

Group-A: Patients treated with Ciprofloxacin/Dexamethasone wick, Group-B: Patients treated with Glycerol/Ichthammol wick
Table IV Comparison of tenderness, discharge and efficacy based on treatment in both genders.

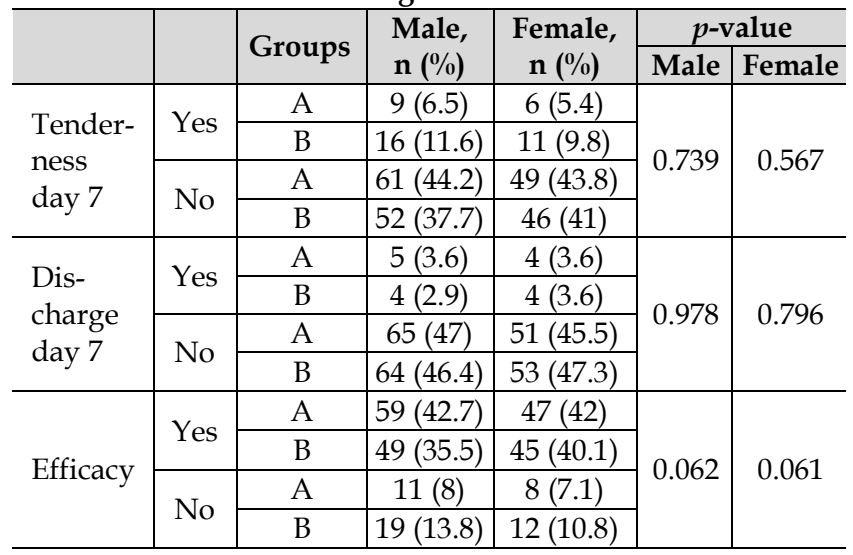

\section{DISCUSSION}

Otitis externa (OE) is a generalized condition of the external auditory canal skin which is characterized by itchy discomfort and discharge/debris in the canal due to generalized oedema and erythema 2. Over whelming cases of otitis externa $(90 \%)$ are bacterial in origin while $10 \%$ cases are of fungal nature 4 .

Commonly known as the swimmers ear it is typically seen in hot, humid climates and in swimmers particularly. Ear canal has a host of protective mechanisms that include its angled nature, a layer of waxy cerumen rich in acid and lysozymes. Any alteration in wax production leading to its deficiency, increases chances of bacterial overgrowth while an excess of cerumen causes retention of water and debris which leads to circumstances very conducive for a bacterial invasion. ${ }^{11,12}$ In swimmers extensive exposure to water coupled with perspiration and high humidity leads to seepage of moisture into the keratin cells under the cerumen. Such conditions once again create an alkaline environment. In addition the skin of external auditory canal is very sensitive resultantly even minor trauma in the form of ear plugs, hearing aid cotton swabs and finger nail trauma leads to break in skin potentially paving the way for future infections. ${ }^{13}$ A localized infection in this region is soon followed by maceration and inflammation leading to the most irritating symptoms of the disease. Chronic recurrent cases of otitis externa may occur as a result of dryness and atrophy of local glands in certain individuals. Otitis externa commonly can exist in combination with mid-dle ear disorders such as acute and chronic otitis media. ${ }^{14}$

Patients undergoing chemo/radiotherapy or suffering from other chronic illnesses most particularly uncontrolled diabetes are particularly vulnerable to 
developing severe form of otitis externa. In such patients there is greater chances of bacterial infection spreading beyond the confines of the soft tissues and eroding the underlying temporal bone. This complication is known as malignant otitis externa. ${ }^{15}$

Pseudomonas species are most commonly reported causing otitis externa. Other organisms that also cause this condition are staphylococcus and streptococcus. Fungi are less commonly involved in causing this condition. Type of discharge can help in identification of the causative organism such as Candida produces white cheesy discharge while Pseudomonas forms green foul smelling discharge. . $^{16,17}$

Multiple treatment options exist for management of otitis externa depending upon its severity and the preference of the treating physician. A thorough suction clearance of the external auditory canal for discharge and debris ensures quick and effective relief whichever mode of treatment is selected. Various agents are used for its treatment however irrigation of the ear canal holds its critics in such a condition and its use is at best controversial. Ciprofloxacin/Dexamethasone combination possess strong antibiotic as well as anti-inflammatory properties both of which are essential for quick and effective relief from the condition. Ciprofloxacin is a quinolone which is effective against all common organisms causing otitis externa while Dexamethasone is a potent glucocorticoid with minimal or no mineralocorticoid activity effectively reducing inflammation and edema within a matter of hours. ${ }^{18}$ Ichthammol/Glycerol is believed to be effective in otitis externa due to the anti-inflammatory action of Ichthammol and dehydrating properties of glycerol on the edematous canal. Anti microbial efficacy of ichthammol is not well known. A study measuring the antibacterial properties of ichthammol glycerol by a growth inhibition test showed it to selectively inhibit gram positive organisms but had negligible activity against the chief offending agent Pseudomonas and E.coli. An important finding was its weakly inhibiting effect on Candida Albicans. Some researchers have found a combination of half acetic acid and hydrocortisone with half $90 \%$ alcohol to be effective in mild cases of OE. ${ }^{8}$

Months of July to October are the peak months for presentation of otitis externa cases in our set up due to increased humidity and soaring daily temperatures. Due to the already burdened specialist OPDs there is a need for a drug that is efficacious and easy to use which will reduce repeated physician visits.
This study was done with the aim of finding an effective treatment option that would relieve the symptoms of such patients quickly while also having minimal side effects.

Although cure rates vary from $87-97 \%$ between ichthammol glycerol and steroid antibiotic wick but considering the cost effective nature of Ichthammol/ glycerol combination a second look at its use is recommended. In our study although the tenderness was reduced significantly in steroid antibiotic group $88 \%$ vs $78.4 \%$ in ichthammol glycerol group ( $p$-value 0.04 ) however the overall difference in efficacy between both groups was not significant ( $p$-value 0.058$)$. This result was similar to the results of a study done by Hornigold who compared the similar two groups in 43 infected patients and found no difference in terms of pain relief, canal wall edema and ear discharge in both groups. ${ }^{19}$ The study authors however do found that approximately $28 \%$ of bacteria were resistant to their choice antibiotic used.

Another study performed by Masood. A used a combination of glycerol/ichthammol with tri adcortyl and ichthammol glycerol for the condition and found simple glycerol/ichthammol combination cost effective as well as less toxic. ${ }^{9}$

Another study done by Abelardo observed that a combination of antibiotic and steroid was more effective in earlier relief of symptoms as compared to steroid alone. ${ }^{20}$ Ahmed et al on the other hand advised using steroid antibiotic drops over ichthammol/glycerol because of its limited anti bacterial properties lea ding to delay in treatment and repeated visits. ${ }^{13}$ Adhikari also made a similar observation to Ahmed et al in concluding that steroid antibiotic combination caused earlier relief of symptoms and less hospital visits as compared to icthammol. ${ }^{21}$

In our study of 250 patients all the patients of both groups had tenderness and discharge initially. On the seventh day of presentation, while tenderness was significantly more in icthammol group ( $p$-value 0.042 ) discharge was almost equally reduced in both groups ( $p$-value 0.08). Overall there was no significant difference in efficacy between both groups ( $p$-value 0.058). Lorent et al observed that the addition of steroid component into the antibiotic preparation for the management of otitis externa was effective in reducing oedema and otorrhea of the effected ears but were similar in efficacy when pain scores were compared. This was also observed in our study where the steroid component and the glycerol component of ichthammol were 
equally effective in reducing oedema and discharge from the ear canal. ${ }^{22}$

Our study could have been improved by the addition of a control to determine the overall efficacy of the drug furthermore we did not study the relief in pain scores of our patients which may be considered a drawback of our study.

\section{CONCLUSION}

While steroid antibiotic wick is significantly efficient in terms reducing tenderness, in terms of overall efficacy and discharge reduction icthammol/glycerol is equally effective. Therefore icthammol glycerine wick is a cheaper and more readily available alternative for management of otitis externa. Alternate hypothesis is thus accepted.

\section{Conflict of Interest: None.}

\section{Authors' Contribution}

MK: Direct, KAAK: Direct, NR: Intellectual, ZH: Intellectual, AA: Intellectual, MW: Intellectual.

\section{REFERENCES}

1. Hajioff D, MacKeith S. Otitis externa. BMJ Clin Evid 2015; 2015(1): 1-5.

2. Szmuilowicz J, Young R. Infections of the Ear. Emerg Med Clin North Am 2019; 37(1): 1-9.

3. Carney As. Otitis externa and otomycosis. In: Gleeson M, Burton MJ, Browning GG, eds. 8nth ed. Scott-Brown's Otorhinolaryngology, Head and Neck surgery. Great Britian: Edward Arnold 2018; 2(1): 953-957.

4. Musa TS, Bemu AN, Grema US, Kirfi AM. Pattern of otitis externa in Kaduna Nigeria. Pan Afr Med J 2015; 21(1): 165-168.

5. Park MK, Nam DW, Byun JY, Hong SM, Bae CH, Lee HY, et al. Differences in antibiotic resistance of mrsa infections in patients with various types of otitis media. J Int Adv Otol 2018; 14(3): 459-463.

6. Villedieu A, Papesh E, Weinberg SE, Teare L, Radhakrishnan J, Elamin WF. Seasonal variation of pseudomonas aeruginosa in culture positive otitis externa in South East England. Epidemiol Infect 2018; 146(14): 1811-1812.

7. Chidlow C, van Bockxmeer J. Otitis externa-climatic associations and evidence-based management strategies for Australian practice. Aust J Rural Health. 2019; 27(3): 251-256.

8. Shrestha BL, Shrestha I, Amatya RC, Dhakal A. Effective treatment of acute otitis externa: a comparison of steroid antibiotic versus $10 \%$ ichthammolglycerine pack. Ind J Otolaryngol Head Neck Surg 2010; 62(4): 350-353.
9. Masood A, Moumoulidis I, Ray S, Chawla O, Panesar J. A randomized controlled trial comparing Triadcortyl with 10\% glycerine-ichthammol in the initial treatment of severe acute otitis externa. Eur Arch Otorhinolaryngol 2008; 265(8): 881-885.

10. Mösges R, Nematian-Samani M, Eichel A. Treatment of acute otitis externa with ciprofloxacin otic $0.2 \%$ antibiotic ear solution. Ther Clin Risk Manag 2011; 7(1): 325-336.

11. Rutka J. Acute otitis externa: treatment perspectives. Ear Nose Throat J 2004; 83(Suppl-4): 20-22.

12. Rowlands S, Devalia H, Smith C, Hubbard R, Dean A. Otitis externa in UK general practice: a survey using the UK General Practice Research Database. Br J Gen Pract 2001; 51(468): 533-538.

13. Ahmed K, Roberts ML, Mannion PT. Antimicrobial activity of Glycerine-chthammol in otitis externa. Clin Otolaryngol Allied Sci 1995; 20(3): 201-203.

14. Serban BA, Stipe KT, Alverson JB, Johnston ER, Priestley ND, Serban MA. A controlled antibiotic release system for the development of single-application otitis externa therapeutics. Gels (Basel, Switzerland) 2017; 3(2): 19-24.

15. Heward E, Cullen M, Hobson J. Microbiology and antimicrobial susceptibility of otitis externa: a changing pattern of antimicrobial resistance. J Laryngol Otol 2018; 132(4): 314-317.

16. Amani S, Moeini M. Comparison of boric acid and combination drug of polymyxin, neomycin and hydrocortisone (polymyxin $\mathrm{NH}$ ) in the treatment of acute otitis externa. J Clin Diagn Res 2016; 10(7): MC01-MC04.

17. Mildenhall N, Honeybrook A, Risoli TJ, Peskoe SB, Kim A, Kaylie D. Clinician adherence to the clinical practice guideline: Acute otitis externa. Laryng 2019; 130(6): 1565-1571.

18. Wall GM, Stroman DW, Roland PS, Dohar J. Ciprofloxacin $0.3 \% /$ dexamethasone $0.1 \%$ sterile otic suspension for the topical treatment of ear infections: a review of the literature. Pediatr Infect Dis J 2009; 28(2): 141-144.

19. Hornigold R, Gillett D, Kiverniti E, Harries M. The management of otitis externa: a randomized controlled trial of glycerol and icthammol ribbon gauze versus topical antibiotic and steroid drops. Eur Arch Otorhinolaryngol 2008; 265(10): 1199-1203.

20. Abelardo E, Pope L, Rajkumar K, Greenwood R, Nunez DA. A double-blind randomized clinical trial of the treatment of otitis externa using topical steroid alone versus topical steroid-antibiotic therapy. Eur Arch Otorhinolaryngol 2009; 266(1): 41-45.

21. Adhikari P, Bhatta R, Bhandari S, Pyakurel Bhatta M. Comparison of steroid. Antibiotic pack and 10\% ichthammol glycerin pack in relieving pain of acute otitis externa in children. Int J Pediatr Otorhinolaryngol 2011; 75(4): 500-503.

22. Lorente J, Sabater F, Rivas MP, Fuste J, Risco J, Gómez M. Ciprofloxacin plus fluocinolone acetonide versus ciprofloxacin alone in the treatment of diffuse otitis externa. The Journal of Laryngology \& Otology. Camb Uni Press 2014; 128(7): 591-598. 